\title{
AVALIAÇÃO TÉCNICA E ECONÔMICA DO REÚSO DE ÁGUAS CINZAS EM APARELHOS SANITÁRIOS
}

\section{TECHNICAL AND ECONOMICAL ASSESSMENT OF GRAY WATER REUSE IN TOILET FLUSH}

\author{
Renata Medici Frayne Cuba ${ }^{1}$; Dilso Pantaleão Manzano ${ }^{2}$ \\ Universidade Federal de Goiás ${ }^{1}$; Universidade do Oeste Paulista ${ }^{2}$; \\ E-mail: renatafrayne@hotmail.com ${ }^{1}$
}

RESUMO O presente trabalho, apoiando-se nas diretrizes ambientais de conservação de água por meio de medidas de reúso de águas cinza, teve como objetivo avaliar a viabilidade técnica e econômica da utilização de águas provenientes de lavadoras de roupa em descargas de vaso sanitário. A pesquisa foi executada no período de 10 meses. Para execução da mesma, foi montado, em uma residência com 4 integrantes adultos, um sistema para o reaproveitamento da água utilizando materiais de baixo custo e encontrados no comércio especializado em materiais de construção ou atividades afins. Como resultado, foi possível reutilizar volume médio de 3.000 litros de água/mês. Devido ao baixo custo da instalação o sistema pode chegar a ser pago em no máximo 22 meses, dependendo do custo da água, porém, adequações ao sistema ainda precisa ser melhor estuda para garantir a adequação de parâmetros como sólidos e nutrientes.

Palavras-chave: Gerenciamento de Água; Racionalização de Água; Sustentabilidade Hídrica.

ABSTRACT - Based in environmental regulations of gray water reclamation, this study aimed to assess the technical and economical feasibility of the use of water from washing machines in domestic toilet flush. The research took ten months and was developed in a residence with four inhabitants, been three adults and a child. Low cost commercial materials were used in the experimental facility. As a result, it was possible to use a mean volume of 3,000 liters of water in a monthly basis. As a consequence of the low cost, a system like this can be paid in 22 months depending on water fares.

Keywords: Water Management; Water Rationalization; Water Sustainability. 


\section{INTRODUÇÃO}

O elevado consumo de água, assim como o acelerado desenvolvimento industrial e tecnológico tem ocasionado à deterioração dos recursos hídricos de tal forma que os impactos negativos já são visíveis nos setores: ambiental, social (principalmente, saúde) e, inclusive, econômico.

No entanto, a má qualidade das águas continentais não é a única preocupação de pesquisadores e especialistas para as próximas décadas, mas, também, a escassez desse recurso que segundo a ONU (2013) “Quase metade da população mundial estará vivendo em áreas com grande escassez de água até $2030 "$.

O Brasil, apesar de seu potencial hídrico, já apresenta problemas com abastecimento de água e, considerando o cenário atual, no ano de 2015 cerca de 55\% dos municípios brasileiros podem vir a sofrer com falta de água (CARDOSO, 2014).

Diante dessa situação de escassez torna-se imprescindível a adoção de modelos de gestão de recursos hídricos com caráter multidisciplinar e participativo que agreguem à gestão da oferta, a gestão da demanda da água (ALBUQUERQUE, 2008)

Para Albuquerque et al. (2008) a gestão da demanda, objetivando o uso eficiente e sustentável da água, pode ser realizada sob dois aspectos: o não estrutural, que se constitui em incentivos econômicos e os estruturais que se baseiam na utilização de alternativas tecnológicas para proporcionar a redução do consumo de água. Segundo Santos et al. (2006) as ações de economia de água são focadas em níveis que abrangem desde sistemas ambientais e bacias hidrográficas até os mais locais como, por exemplo, edificações.

No caso das edificações as estratégias de conservação de água englobam diferentes práticas que vão desde o uso racional da água até mesmo à utilização de fontes alternativas como as águas de chuva e o reúso de águas cinzas.

Águas cinzas segundo Fiori et al. (2006) são aquelas provenientes de lavatórios, chuveiros, tanques e máquinas de lavar roupa e louça que devido as suas características poderiam ser utilizadas para fins menos nobres.

De acordo com Hafner (2007) (apud HASTENREITER, 2013) no Brasil entre as atividades que mais consomem água em uma residência encontram-se as bacias sanitárias, que representam cerca de $22 \%$ da demanda doméstica total, seguidas pela pia da cozinha com $18 \%$ e a máquina de lavar roupas com $9 \%$.

Sendo assim, a substituição da água potável nos vasos sanitários por uma água de qualidade inferior, a partir do reúso, pode constituir-se em uma medida de impacto 
significativo na redução da captação de água natural (COHIN et al., 2007) já que esses sistemas possibilitam o complemento ao abastecimento urbano preservando a água potável para atendimento de usos mais nobres como a ingestão direta ou o preparo de alimentos (PAES; SILVA; PRIANTE FILHO, 2010).

Quantitativamente, May (2009) calculou que a economia de água potável poderia ser de $1 / 3$ do volume necessário para atender o consumo doméstico.

No entanto, ao analisar a literatura foi possível constatar obstáculos referentes à implantação de sistemas de reúso no Brasil, sendo eles: carência de legislação e normatização desenvolvidas, aceitação dos usuários, custos do sistema e qualidade da água a ser reutilizada.

Com relação à legislação pertinente ainda são poucos os estados que apresentam leis e regulamentos de forma a padronizar o reúso destes efluentes. Entre eles, pode-se citar Paraná (Lei № 10.785/2003), Rio de Janeiro (Lei № 2.856/2011 - Niterói), São Paulo (Lei № 6.110/2011 - Bauru).

Cabe salientar também que não há, no Brasil, uma norma específica sobre os requisitos necessários para a implantação de sistemas prediais de reúso de água proveniente de máquinas de lavar roupas, porém, a Associação Brasileira de Normas Técnicas (ABNT) na NBR 13969/1997 - projeto, construção e operação de tanques sépticos - contempla aspectos básicos a serem observados quanto à concepção de sistemas de reúso, como segue: planejamento do sistema de reúso, usos previstos para o esgoto tratado, volume de esgoto a ser reutilizado, grau de tratamento necessário, sistema de preservação e de distribuição, manual de operação e treinamento dos responsáveis.

Referente à aceitação do usuário ao reúso de águas cinzas, Cohim e Cohim (2007) (apud PAES; SILVA; PRIANTE FILHO, 2010) verificaram que esta é maior quando a água é oriunda da própria residência em contraposição à possibilidade de se utilizar águas originadas de outras fontes como bairros ou áreas públicas comunitárias.

Já os custos dependem, segundo Mierzwa et al. (2006), da infraestrutura adotada que abrange a rede dupla de abastecimento, necessária para a água não potável e a coleta separada das águas cinzas, incluindo as unidades complementares de bombeamento e acondicionamento da água de reúso.

Com relação ao tratamento, este é específico para cada situação sendo necessário ser avaliado individualmente, no entanto, segundo a NBR 13969 "nos casos simples de reúso menos exigente (por exemplo, descarga de vasos sanitários) podese prever o uso de água de enxague das 
máquinas de lavar, apenas desinfetando, reservando aquelas águas e recirculando-as ao vaso, em vez de enviá-las para o sistema de esgoto para posterior tratamento" (ABNT, 1997, p. 22).

Neste sentido, o presente trabalho apresenta proposta de um sistema experimental de reutilização da água de lavadoras de roupa em vasos sanitários.

\section{MATERIAL E MÉTODOS}

\subsection{SISTEMA DE REÚSO}

O sistema de reúso foi montado no bairro Parque dos Pinheiros em Álvares Machado numa residência com quatro pessoas adultas.

Na Figura 1 é ilustrado esquema geral do sistema utilizado.

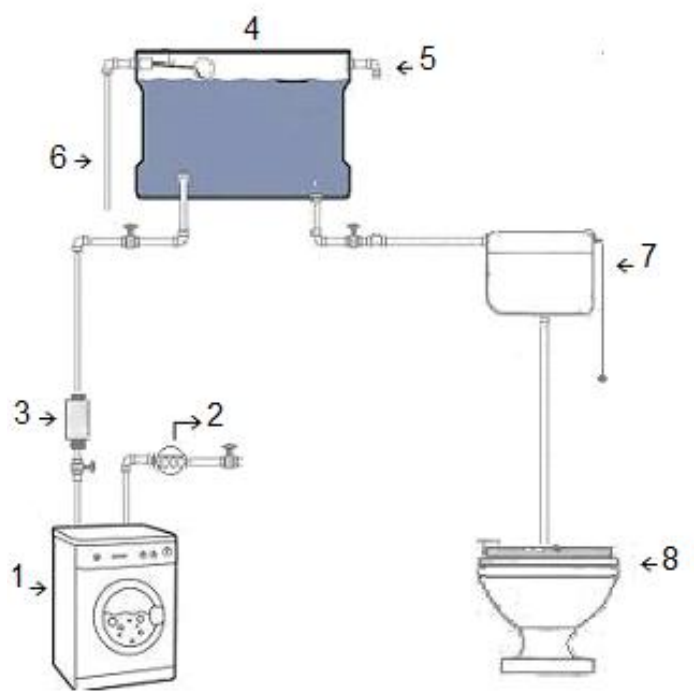

Figura 1. Sistema de reúso utilizado Fonte: Próprios autores

O sistema utilizado foi relativamente simples, haja vista a necessidade de que o mesmo fosse o mais econômico possível.
De forma geral, o sistema de reúso foi composto por uma máquina de lavar roupas, com capacidade de $7 \mathrm{~kg}$ (1) e um reservatório com capacidade de 500L (4), alocado na laje da lavanderia e conectado ao sistema de descarga de água de dois vasos sanitários (8) da moradia, sendo um deles alimentado por caixa de descarga externa sem engate (7), com capacidade de 9,0 L, e outro por válvula do tipo hidra (não ilustrado).

A escolha da capacidade volumétrica do reservatório foi baseada em informações contidas no manual de instruções da máquina de lavar com relação ao consumo máximo de água pelo equipamento, aproximadamente $212 \mathrm{~L}$ por lavagem, nas condições: vazio, nível alto e enxague simples.

Como a bomba da máquina não apresentou capacidade de recalque suficiente para elevar a água até o reservatório instalado a uma altura de $3 \mathrm{~m}$, foi necessário instalar na saída de água da máquina um pressurizador de água (3), comumente utilizado para chuveiros, com as seguintes características: equipamento com acionamento automático, ou seja, liga e desliga com o abrir e fechar das torneiras através de sistema de fluxostato acionado por fluxo mínimo de $2 \mathrm{Lmin}^{-1}$ e pressões mínima e máxima de 2 e 15 m.c.a, respectivamente. 
Em caso de desabastecimento decorrente de volume de água insuficiente ou falha da bomba de recalque da lavadora, o reservatório de reúso também foi conectado ao sistema público de distribuição domiciliar de água (6) assim como, a um extravasor (5) em caso de mau funcionamento da válvula tipo bóia.

Para medir com maior precisão a quantidade de água utilizada pela máquina e que ficou disponível para o reúso foi instalado um hidrômetro (2) cedido pela Companhia de Saneamento Básico do Estado de São Paulo (SABESP).

Na Figura 2 é apresentada foto de parte do sistema utilizado.

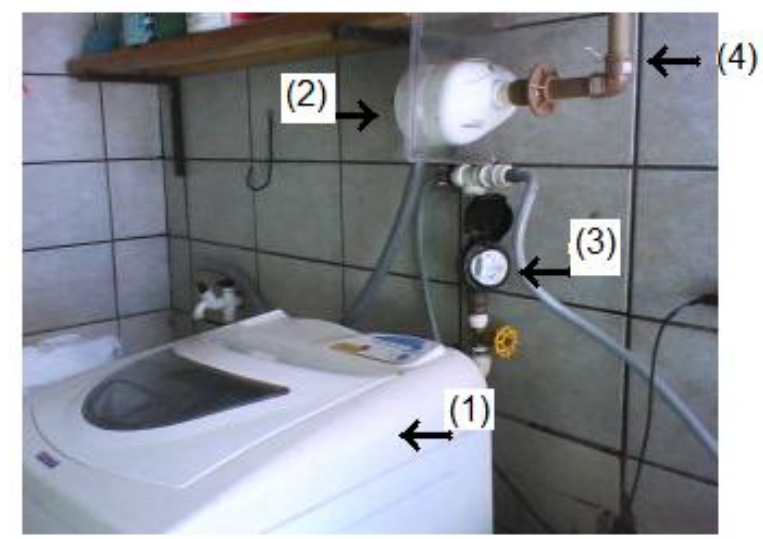

Figura 2. Foto com visualização parcial do esquema de reúso.

Fonte: Próprios autores

Descrição das unidades: (1) Máquina de lavar; (2) Pressurizador para bombear água de reúso; (3) hidrômetro; (4) tubulação de PVC utilizada para condução da água da lavadora para o sistema de armazenamento (não visualizado).
Na Figura 3 é apresentada foto do reservatório utilizado no experimento.

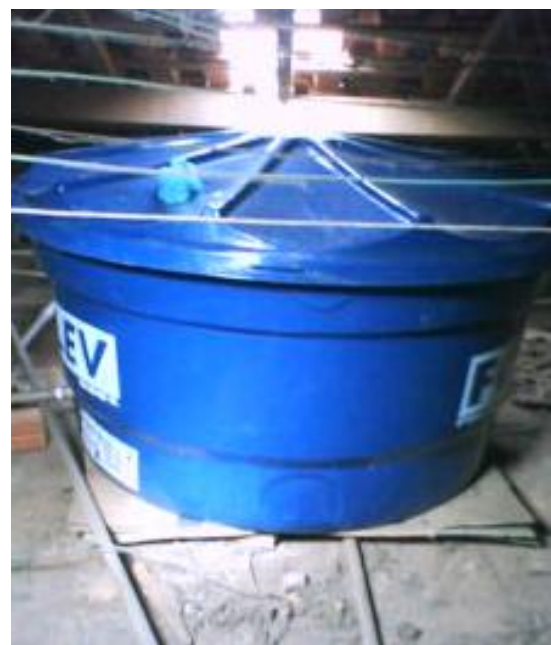

Figura 3. Foto do reservatório de água de reúso

Fonte: Próprios autores

\subsection{QUALIDADE DA ÁGUA DE REÚSO}

Para verificar se a água proveniente da lavadora se enquadrava dentro dos padrões aceitos para reúso em bacias sanitárias, foram realizadas no Laboratório de Análises de Água da Universidade do Oeste Paulista (UNOESTE) medidas de $\mathrm{pH}$, nitrato, nitrito, cloro residual livre, fósforo total, sólidos totais dissolvidos, sólidos suspensos totais e turbidez.

Os resultados foram comparados com os limites estabelecidos tanto pela NBR 13.969/97 assim como pelo Sindicato da Indústria da Construção (SINDUSCON, 2005), sendo esta última referência adotada pelo fato de contemplar um número maior de parâmetros.

As análises foram realizadas com água proveniente, diretamente, do reservatório de reúso em intervalo de tempo de três meses, 
totalizando três análises ao longo do período de estudo.

\subsection{TRATAMENTO DA ÁGUA DE REÚSO}

O tratamento consistia na remoção dos sólidos em suspensão levados com a água durante a operação de lavagem das roupas, principalmente fiapos, seguida pela cloração da água. Esse último processo, foi necessário para evitar o mau cheiro decorrente da decomposição dos resíduos incorporados à água durante a operação de lavagem de roupa assim como para garantir a qualidade microbiológica.

Para a remoção dos fiapos, acondicionou-se um filtro preenchido com feltro, normalmente utilizado em equipamentos de ar condicionado, antes da entrada da água no reservatório enquanto que a cloração foi realizada por meio de um flutuador contendo pastilha de cloro. A vantagem desse flutuador é que a pastilha se dissolve lentamente na água de reúso promovendo o seu tratamento contínuo e a mesma pode ser facilmente adquirida em casas que revendem materiais para piscinas.

\section{RESULTADOS E DISCUSSÃO}

\subsection{REÚSO DE ÁGUA}

O experimento foi levado a cabo durante o período de 10 meses. Nesse período a lavadora de roupas não apresentou nenhum tipo de problemas e a quantidade de água utilizada foi suficiente para abastecer ambos os sanitários da casa.

No Quadro 1 é apresentado o volume de água que foi redirecionado para o tanque de reúso.

QUADRO 1. Volume de água utilizado na lavadora de roupas durante o período de estudo.

\begin{tabular}{|c|c|c|c|}
\hline Mês & $\begin{array}{c}\text { Água Reutilizada } \\
\left(\mathbf{m}^{\mathbf{3}}\right)\end{array}$ & Mês & $\begin{array}{c}\text { Água Reutilizada } \\
\left(\mathbf{m}^{\mathbf{3}} \mathbf{)}\right.\end{array}$ \\
\hline 1 & 2,85 & 6 & 3,25 \\
\hline 2 & 3,51 & 7 & 2,81 \\
\hline 3 & 3,78 & 8 & 3,23 \\
\hline 4 & 3,62 & 9 & 3,91 \\
\hline 5 & 2,93 & 10 & 3,42 \\
\hline
\end{tabular}

Fonte: Próprios autores

A partir dos dados apresentados no Quadro 1 pode-se verificar que durante o período de estudo foi possível fazer um reúso médio de $3,31 \mathrm{~m}^{3} \mathrm{mês}^{-1}$ de água.

Desta forma, considerando um consumo médio mensal por domicílo ${ }^{1}$ de 20 $\mathrm{m}^{3} \mathrm{mês}^{-1}$, esse volume representa $17 \%$ da água fornecida pela SABESP.

Fazendo a projeção dos dados para o período de um ano, pode-se estimar que os 6.100 domicílios da cidade de Álvares Machado (IBGE, 2014) deixariam de consumir, anualmente, $244.000 \mathrm{~m}^{3}$ de água tratada poupando, desta forma, o manancial da retirada do mesmo volume.

Com relação à economia financeira, o cálculo para o período foi realizado levando-

\footnotetext{
${ }^{1}$ Neste caso foi adotado um número médio de quatro pessoas por domicílio
} 
se em consideração o consumo mensal de água e a tarifa paga para o mês em estudo.

A tarifa utilizada nos cálculos considerou a água cobrada por faixas de consumo, o valor cobrado pelo esgoto gerado e os impostos embutidos na cobrança, desta forma, o montante economizado durante o período de estudo foi, igualmente, de $17 \%$ ou seja, uma economia per capita de 4,25\%.

Estudo semelhante realizado por Sella (2011) estimou uma economia de $29 \%$ no consumo, porém, o estudo teve como base uma casa com dez pessoas, o que equivale à economia per capta de $2,9 \%$.

Nesse sentido, pode-se verificar que a economia financeira obtida foi satisfatória.

Para verificar o tempo de retorno do investimento foi computado o total investido em material assim como o montante economizado durante o período de estudo.

Cabe ressaltar que nos cálculos de investimento não foi considerada a mão de obra para a montagem do sistema, pois esta foi executada pelos proprietários.

Desta forma, ao se comparar o total gasto para a montagem do sistema e o valor economizado nos 10 meses em que o mesmo se encontrou em operação, uma família, com as mesmas características que a estudada, levaria em média 22 meses para pagar o investimento, isso, sem levar em consideração possíveis correções nas tarifas de água.

Esses resultados são compatíveis com resultados apresentados em estudos realizados por Lazzarotto (2013), Mierzwa et al. (2006) e Nosé (2008) que obtiveram, respectivamente, períodos de retorno de $2,75,2,4$ e 1,63 anos. No entanto, cabe ressaltar que os autores focaram empreendimentos maiores cuja necessidade de uma concepção mais complexa de reúso pode acarretar aumento nos gastos e, consequentemente, maiores períodos de retorno.

Não foi possível encontrar na literatura trabalhos focados em sistemas simplificados, motivo pelo qual, não se fez as devidas comparações.

\subsection{CARACTERÍSTICAS FÍSICO-QUÍMICAS DA ÁGUA DE REÚSO}

Os resultados das análises físicoquímicas realizadas na água de reúso assim como os valores de referência para águas classe 1 , encontram-se apresentados no Quadro 2. 
QUADRO 2 - Resultados das análises físicoquímicas da água de reúso

\begin{tabular}{|c|c|c|c|}
\hline & & \multicolumn{2}{|c|}{ Valor de Referência } \\
\hline $\begin{array}{c}\text { Parâmetr } \\
\text { o }\end{array}$ & $\begin{array}{c}\text { Valor } \\
\text { observado }\end{array}$ & $\begin{array}{c}\text { SINDUSCO } \\
\text { N (2005) }\end{array}$ & $\begin{array}{c}\text { NBR } \\
\text { 13.969/97 } \\
\text { item 5.6.4 }\end{array}$ \\
\hline $\mathrm{pH}$ & 7.01 & $6,00-9,00$ & - \\
\hline Turbidez & $10 \mathrm{NTU}$ & $\leq 2 \mathrm{NTU}$ & $\leq 10 \mathrm{NTU}$ \\
\hline $\begin{array}{c}\text { Cloro } \\
\text { Residual } \\
\text { Livre }^{1} \\
\end{array}$ & 7,00 & - & - \\
\hline $\begin{array}{c}\text { Nitrato - } \\
\mathrm{N}^{1}\end{array}$ & 13,00 & $<10$ & - \\
\hline $\begin{array}{c}\text { Nitrito - } \\
\mathrm{N}^{1}\end{array}$ & 0,05 & $<1$ & - \\
\hline $\begin{array}{l}\text { Fósforo } \\
\text { total }(\mathrm{P})^{1}\end{array}$ & 17,76 & $<0,1$ & - \\
\hline $\begin{array}{c}\text { Sólidos } \\
\text { Totais } \\
\text { dissolvido } \\
s^{1}\end{array}$ & 646,00 & $<500$ & - \\
\hline $\begin{array}{c}\text { Sólidos } \\
\text { Suspenso } \\
\text { s Totais }^{1}\end{array}$ & 27,5 & $<5$ & - \\
\hline $\begin{array}{c}\text { Odor e } \\
\text { aparência }\end{array}$ & $\begin{array}{c}\text { Não } \\
\text { desagradávei } \\
\mathrm{S}\end{array}$ & $\begin{array}{c}\text { Não } \\
\text { desagradáv } \\
\text { eis }\end{array}$ & - \\
\hline $\begin{array}{l}\text { Coliforme } \\
\text { s fecais }^{2}\end{array}$ & - & - & 500 \\
\hline
\end{tabular}

Com relação aos resultados físicoquímicos pode-se verificar que a norma NBR 13.969/97 é bem mais flexível, o que permitiria o enquadramento do efluente tratado, porém, ao comparar os resultados obtidos com os valores de referência propostos pelo SINDUSCON (2005) pode-se verificar a não adequação de alguns parâmetros, como por exemplo: nitrato, fósforo, sólidos e turbidez.

As elevadas concentrações de fósforo e nitrato podem estar associadas à característica do sabão em pó, assim como, do amaciante, frequentemente, utilizados na lavagem das roupas.

No caso do fósforo esse composto é, geralmente, adicionado na forma de tripolifosfato de sódio (STPP) cuja função é a de neutralizar o cálcio e magnésio, geralmente, presentes na água e que dificultam a ação do detergente. Já, o nitrogênio, pode estar associado à presença de enzimas, que são adicionadas em algumas marcas de sabão em pó, que também têm o intuito de melhorar a eficiência de tais compostos.

Além do mais, os amaciantes de roupas, também apresentam na sua composição compostos a base de fósforo e nitrogênio.

O controle das formas de nitrogênio e fósforo, segundo o SINDUSCON (2005) visa evitar a proliferação de algas e filmes biológicos, que podem formar depósitos em tubulações, peças sanitárias, reservatórios, tanques etc. Geralmente, o tratamento envolve a utilização de sistemas mais complexos e custosos, visto a dificuldade na sua remoção.

Neste sentido, a alternativa mais viável para tentar enquadrar esses parâmetros aos sugeridos pelo SINDUSCON (2005), seria a troca do detergente em pó, por outros cuja composição apresente menor conteúdo de fósforo, assim como, a 
diminuição na quantidade de sabão e amaciante utilizados por ciclo de lavagem.

Além do mais, a presença de cloro residual, nesta situação, é um fator importante, já que este pode inviabilizar o crescimento de tais organismos devido a sua ação oxidante.

Com relação aos sólidos em suspensão, o SINDUSCON (2005, p.53) explica que estes podem gerar "problemas de sedimentação, o que causaria odores devido à decomposição de matéria orgânica, obstrução e presença de materiais flutuantes", desta forma, a adequação do sistema para este parâmetro, poderia ser alcançada por meio da modificação da unidade de coleta de resíduos, utilizando, por exemplo, um filtro com leito filtrante de menor porosidade, como, por exemplo, filtros específicos para caixa d'água.

Esse tipo de equipamento pode ser facilmente encontrado em casas especializadas, mas o preço do equipamento elevaria o custo do sistema proposto em média de 10 a 15\%, dependendo da marca escolhida.

Já os sólidos dissolvidos, acredita-se que esses sejam resultados dos produtos utilizados para a lavagem da roupa, sendo esses os mais difíceis de adequarem ao recomendado, visto, os custos envolvidos na sua remoção, porém, acredita-se que a diminuição na quantidade de produtos utilizados durante a lavagem de roupas, venha a auxiliar nessa diminuição.

Com relação aos ensaios microbiológicos, esses não foram realizados, visto que a concentração de cloro residual presente nas amostras de água foi suficiente para garantir ação bactericida, eliminando, desta forma, a presença destes organismos no meio.

Durante o período de estudo, não foi detectado odor desagradável, tanto próximo do reservatório assim como na água que ficava no vaso sanitário após a descarga.

Essa situação deve-se, principalmente, à concentração de cloro residual no reservatório (SINDUSCON, 2005).

Também, segundo os usuários do sistema, o mesmo não apresentou formações de espuma no vaso sanitário durante a descarga de água, outra recomendação feita pela SINDUSCON (2005).

\subsection{MANUTENÇÃO DO SISTEMA}

Segundo os usuários do sistema a manutenção do mesmo não apresentou maiores complicações.

A limpeza do filtro foi realizada a cada quinze dias e a substituição da pastilha de cloro (200g), uma vez ao mês. Porém, cabe ressaltar que o acesso ao reservatório, no estudo específico, era relativamente fácil, visto que o mesmo não se encontrava entre o telhado e a laje da residência, sendo essa 
uma condição fundamental ao fazer a escolha da locação das unidades de tratamento.

\section{CONCLUSÕES}

O sistema de reúso utilizado rendeu economia, de aproximadamente $17 \%$ no consumo de água, no período de 10 meses, para uma família de quatro adultos.

Devido à utilização de materiais de baixo custo, o tempo de retorno do investimento foi de até 22 meses. Apesar de a qualidade da água de reúso estar adequada para os padrões propostos pela NBR 13.969/97, quando levadas em consideração as recomendações feitas pelo SINDUSCON (2005), verifica-se que melhorias no sistema ainda devem ser estudas, principalmente com relação à concentração de sólidos e nutrientes.

A diminuição da concentração de compostos fosfatados e nitrogenados na água poderia ser realizada utilizando-se produtos com menor quantidade destes compostos assim como pela diminuição na quantidade do detergente utilizado, visto que a adoção de sistemas que possibilitem a remoção de tais compostos seria inviável ponto de vista econômico.

\section{CONSIDERAÇÕES FINAIS}

Os eventos de escassez de água vivenciados por municípios brasileiros nos últimos tempos demonstraram a urgência em se adotar uma gestão das águas não somente a qualidade, mas também à quantidade.

Porém, essas ações devem ser realizadas em diferentes níveis que vão desde a bacia hidrográfica até mesmo ao uso mais pontual, como no caso de residências.

Nesse sentido, o reúso de águas cinza em atividades menos exigentes, como as descargas de sanitários, pode vir a ser uma alternativa local viável para diminuir a pressão sobre os recursos hídricos, porém, tais medidas devem também considerar a utilização de materiais de baixo custo de forma a viabilizar seu uso, principalmente, entre usuários do setor de menor poder aquisitivo, visto que sistemas mais sofisticados de reúso já são adotados por construções com maiores padrões econômicos.

\section{AGRADECIMENTOS}

Os autores agradecem à UNOESTE pelo fomento financeiro concedido na forma de bolsa de iniciação científica e para a aquisição dos materiais, que possibilitaram a execução deste trabalho.

\section{REFERÊNCIAS}

AlBUQUERQUE, T. M. A. et al. Análise multicriterial de alternativas tecnológicas para redução do consumo de água. Revista Brasileira de Recursos Hídricos, v.13, n.4, p.99-110, 2008. Disponível em: <http://www.abrh.org.br/SGCv3/UserFiles/S umarios/964797cff3db5d65f44f58e52a74268 a_6779f2b7c1c9a509c8235e24753e270f.pdf $>$. Acesso em: Acesso em: 23 jun. 2014. 
CARDOSO, T. Nível baixo dos reservatórios Risco de falta da água e eletricidade. Ciência e Tecnologia, 2014. Disponível em: <http://cienciasetecnologia.com/nivelbaixod ereservatoriosperigofaltaaguaeletrecidade/\#i xzz35P3XHTy5>. Acesso em: 23 jun. 2014

COHIN, E. et al. Avaliação de risco à saúde do reúso de águas residuárias tratadas em descargas de vaso sanitário; a rota dos aerossóis. In: CONGRESSO BRASILEIRO DE ENGENHARIA SANITÁRIA E AMBIENTAL, 24., 2007, Belo Horizonte/MG. Disponível em: <http://teclim.ufba.br/site/material_online/p ublicacoes/pub_art51.pdf>. Acesso em: 21 jun. 2014.

DI GIULIO, G. Águas: Brasil precisa difundir tecnologias e ampliar políticas públicas. Inovação Uniemp, Campinas, v. 3, n. 1, feb. 2007 . Disponível em: <http://inovacao.scielo.br/scielo.php?script= sci_arttext\&pid=S180823942007000100020\& Ing=es\&nrm=iso >. Acesso em: 22 jun. 2014.

FIORI, S. et al. Avaliação qualitativa e quantitativa do reúso de águas cinzas em edificações. Ambiente Construído, Porto Alegre, v. 6, n. 1, p. 19-30, jan./mar. 2006.

HASTENREITER, T. A. Estudo de viabilidade técnica e econômica de implantação de um sistema de reuso de água cinza para fim não potável em edificação empresarial. 2013. 125f. Trabalho (Conclusão de Curso) Universidade Federal do Espírito Santo, Vitória, ES. Disponível em: <http://www.ct.ufes.br/dea/dea/files/estud o\%20de\%20viabilidade\%20t\%c3\%89cnica\%2 0e\%20econ\%c3\%94mica\%20de\%20implanta \%c3\%87\%c3\%830\%20de\%20um\%20sistema \%20de\%20reuso\%20de\%20\%c3\%81gua\%20c inza\%20para\%20fim\%20n\%c3\%83o\%20pot\% c3\%81vel\%20em\%20_tain\%c3\%a1\%20alves $\% 20$ hastenreiter.pdf>. Acesso em: 23 jun. 2014.
IBGE. Cidades. Disponível em: $<$ http://cidades.ibge.gov.br/xtras/perfil.php? codmun=350130 > . Acesso em: 02 nov. 2014.

LAZZAROTTO, P.R.R. Reúso de águas cinzas: implantação do sistema em um prédio residencial. 2013. 118f. Trabalho (Conclusão de Curso) - Universidade Federal do Rio Grande do Sul. Disponível em: <http://www.lume.ufrgs.br/bitstream/handl e/10183/96310/000914987.pdf?sequence=1 >. Acesso em: 23 jun. 2014.

MAY, S. Caracterização, tratamento e reúso de águas cinzas e aproveitamento de águas pluviais em edificações. 2009. 200f. Tese (Doutorado) Escola Politécnica da Universidade de São Paulo, SP.

MIERZWAR, J.C. et al. Avaliação econômica dos sistemas de reúso de água em empreendimentos imobiliários. In: CONGRESO DE LA ASOCIACION DE INGENIERIA SANITARIA Y AMBIENTAL. PUNTA DEL ESTE - URUGUAY, 30., 2006. Disponível em:

<http://www.bvsde.paho.org/bvsaidis/urugu ay30/BR08519_Mierzwa.pdf>. Acesso em: 22 jun. 2014.

NOSÉ, D. Aproveitamento de águas pluviais e reúso de águas cinzas em condomínios residenciais. 2008. 120 f. Trabalho (Conclusão de Curso) - Universidade Anhembi Morumbi, São Paulo. Disponível em: $<$ http://engenharia.anhembi.br/tcc-08/civil12.pdf>. Acesso em: 21 jun. 2014.

ONU. Quase metade da população mundial viverá em áreas com grande escassez de água até 2030, alerta ONU. 2013. Disponível em: <http://www.onu.org.br/quase-metadedapopulacao-mundial-viveraemareas commgrande-escassez-deaguaate2030alertaonu/>. Acesso em: 22 jun. 2014

PAES, R. P.; SILVA, G. C. O.; PRIANTE FILHO, N. Aplicação de tecnologias de conservação do uso da água através do reuso - estudo de 
caso Cuiabá, MT. Revista Brasileira de

Recursos Hídricos, v.15, n.3, p.97-107, 2010.

Disponível

em:

<http://www.abrh.org.br/SGCv3/UserFiles/S

umarios/f0b76ddadbaed7943dd09475abf177

51_fea7bead73a9ef872577826e91e88f73.pd

$\mathrm{f}>$. Acesso em: 22 jun. 2014.

SANTOS, D. C. et al. Hierarquização de medidas de conservação de água em edificações residenciais com o auxílio de análises multicritério. Ambiente Construído, v.6, n.1, p.31-47, 2006. Disponível em: $<$ http://seer.ufrgs.br/index.php/ambientecon struido/article/view/3678/2044>. Acesso em: 22 jun. 2014.

SELLA, M.B. Reúso de águas cinzas: avaliação da viabilidade da implantação do sistema em residências. 2011. 85 f. Trabalho (Conclusão de Curso) - Escola de Engenharia da Universidade Federal do Rio Grande do Sul, RS. Disponível em: <http://www.lume.ufrgs.br/bitstream/handle/10 183/34521/000789725.pdf>. Acesso em: 01 nov. 2014.

SINDUSCON. Conservação e reúso de água em edificações. 2005. Disponível em: <http://www.sindusconsp.com.br>. Acesso em: 23 jun. 2014. 